\title{
Multicentre evaluation of a new point-of-care test for the determination of NT-proBNP in whole blood
}

\author{
Christian Zugck ${ }^{1}$, Manfred Nelles ${ }^{1}$, Hugo A. \\ Katus ${ }^{1}$, Paul O. Collinson ${ }^{2}$, David C. Gaze ${ }^{2}$, Bert \\ Dikkeschei ${ }^{3}$, Eberhard Gurr ${ }^{4}$, Wiebke Hayen ${ }^{4}$, \\ Markus Haass ${ }^{5}$, Christoph Hechler ${ }^{5}$, Viviane \\ van Hoof ${ }^{6}$, Khadija Guerti ${ }^{6}$, Carl van Waes ${ }^{6}$, \\ Gert Printzen ${ }^{7}$, Kai Klopprogge ${ }^{8}$, Ilse Schulz ${ }^{9}$ \\ and Rainer Zerback ${ }^{9, *}$ \\ ${ }^{1}$ Abteilung für Kardiologie, Angiologie und \\ Pulmonologie, Universitätsklinikum Heidelberg, \\ Heidelberg, Germany \\ ${ }^{2}$ Chemical Pathology, St. George's Hospital, \\ London, UK \\ ${ }^{3}$ Isala Klinieken, Zwolle, The Netherlands \\ ${ }^{4}$ Abteilung für Klinische Chemie und Zentrallabor, \\ Zentralkrankenhaus Links der Weser, Bremen, \\ Germany \\ ${ }^{5}$ Kardiologie, Theresienkrankenhaus Mannheim, \\ Mannheim, Germany \\ ${ }^{6}$ Centraallabor, Universitair Ziekenhuis Antwerpen, \\ Edegem, Belgium \\ ${ }^{7}$ Institut für Klinische Chemie, Inselspital Bern, Bern, \\ Switzerland \\ ${ }^{8}$ Exco Engineering Systemtechnik und Consulting \\ $\mathrm{GmbH}$, Maxdorf, Germany \\ ${ }^{9}$ Evaluation Department Near Patient Testing, Roche \\ Diagnostics $\mathrm{GmbH}$, Mannheim, Germany
}

\begin{abstract}
Background: The Roche CARDIAC proBNP point-ofcare (POC) test is the first test intended for the quantitative determination of $\mathrm{N}$-terminal pro-brain natriuretic peptide (NT-proBNP) in whole blood as an aid in the diagnosis of suspected congestive heart failure, in the monitoring of patients with compensated left-ventricular dysfunction and in the risk stratification of patients with acute coronary syndromes.

Methods: A multicentre evaluation was carried out to assess the analytical performance of the POC NTproBNP test at seven different sites.

Results: The majority of all coefficients of variation (CVs) obtained for within-series imprecision using native blood samples was below $10 \%$ for both 52 samples measured ten times and for 674 samples measured in duplicate. Using quality control material, the majority of $\mathrm{CV}$ values for day-to-day imprecision were below $14 \%$ for the low control level and below $13 \%$ for the high control level. In method comparisons for four lots of the POC NT-proBNP test with the lab-

\footnotetext{
*Corresponding author: Dr. Rainer Zerback, Roche Diagnostics $\mathrm{GmbH}$, Evaluation Near Patient Testing (Dept. NR-EA), Sandhofer Straße 116, 68305 Mannheim, Germany

Phone: + 49-621-759-4191, Fax: +49-621-759-6259,

E-mail: rainer.zerback@roche.com
}

oratory reference method (Elecsys proBNP), the slope ranged from 0.93 to 1.10 and the intercept ranged from 1.8 to 6.9. The bias found between venous and arterial blood with the POC NT-proBNP method was $\leq 5 \%$. All four lots of the POC NT-proBNP test investigated showed excellent agreement, with mean differences of between $-5 \%$ and $+4 \%$. No significant interference was observed with lipaemic blood (triglyceride concentrations up to $6.3 \mathrm{mmol} / \mathrm{L}$ ), icteric blood (bilirubin concentrations up to $582 \mu \mathrm{mol} / \mathrm{L}$ ), haemolytic blood (haemoglobin concentrations up to $62 \mathrm{mg} / \mathrm{L}$ ), biotin (up to $10 \mathrm{mg} / \mathrm{L}$ ), rheumatoid factor (up to $42 \mathrm{IU} / \mathrm{mL}$ ), or with 50 out of 52 standard or cardiological drugs in therapeutic concentrations. With bisoprolol and BNP, somewhat higher bias in the low NT-proBNP concentration range $(<175 \mathrm{ng} / \mathrm{L})$ was found. Haematocrit values between $28 \%$ and $58 \%$ had no influence on the test result. Interference may be caused by human anti-mouse antibodies (HAMA) types 1 and 2. No significant influence on the results with POC NT-proBNP was found using volumes of 140-165 $\mu \mathrm{L}$. High NT-proBNP concentrations above the measuring range of the POC NT-proBNP test did not lead to false low results due to a potential highdose hook effect.

Conclusions: The POC NT-proBNP test showed good analytical performance and excellent agreement with the laboratory method. The POC NT-proBNP assay is therefore suitable in the POC setting.

Clin Chem Lab Med 2006;44:1269-77.

Keywords: analytical performance; brain natriuretic peptide (BNP); congestive heart failure; natriuretic peptides; N-terminal proBNP (NT-proBNP); point-ofcare testing.

\section{Introduction}

Chronic heart failure (CHF) is the only cardiovascular disease that is still characterised by increasing incidence and prevalence $(1,2)$. Therefore, accurate diagnosis and adequate management of such patients have an important impact on healthcare systems.

Consequently, the guidelines of the European Society of Cardiology recommend analysis of brain natriuretic peptide (BNP) or $\mathrm{N}$-terminal proBNP (NTproBNP), in combination with assessment of symptoms and clinical findings, electrocardiogram, chest $\mathrm{X}$-ray and Doppler-echocardiography, when evaluating patients with suspected heart failure $(3,4)$. Numerous retrospective and prospective clinical studies have demonstrated that a wide range of clinical applications related to heart failure (and acute coronary syndromes), including diagnosis, monitoring 


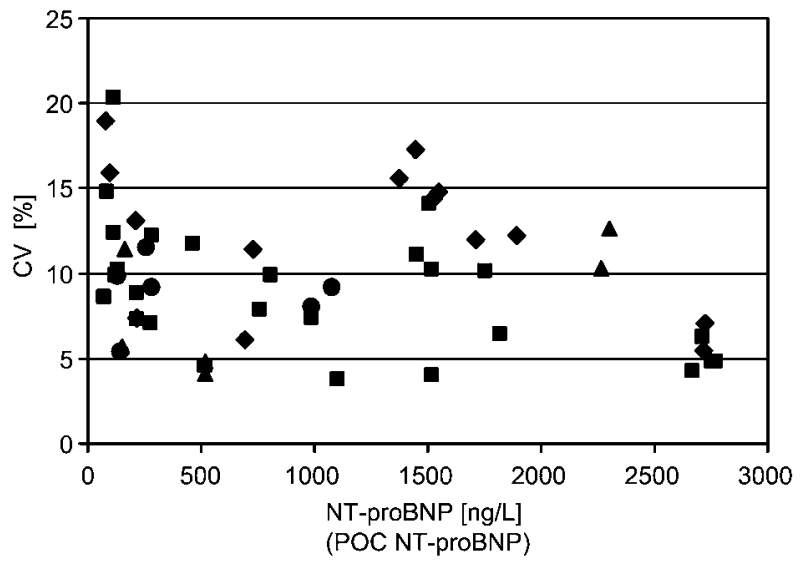

Figure 1 Within-series imprecision of POC NT-proBNP using patient samples ( $\mathrm{n}=10$ replicates). $\square$ lot 226382-30; lot 226383-30; $\Delta$ lot 226384-30; lot 226396-30. CV, coefficient of variation

and prognosis, may benefit from the determination of these peptides.

NT-proBNP testing has been shown to be useful in ruling out acute heart failure in the emergency department (5-8) and to improve the diagnostic accuracy of heart failure in the primary care setting $(9,10)$. Plasma NT-proBNP is a powerful predictor of in-hospital and long-term mortality of patients with severe heart failure (11-16). Furthermore, a small pilot study showed that adjustment of heart failure therapy guided by serial measurements of NT-proBNP can improve outcome compared to intensive clinically guided treatment (17).

The physiologically active hormone BNP and the inactive NT-proBNP are released from the myocardium as a response to myocardial stretch. Both are cleavage products of the precursor peptide proBNP. NT-proBNP was shown to have a similar or even better correlation to left ventricular dysfunction as BNP (18). In addition, NT-proBNP is stable for up to at least $72 \mathrm{~h}$ after blood sampling, and has a longer half-life and consequently higher plasma levels compared to BNP (19-21).

According to the guidelines of the National Academy of Clinical Biochemistry on biomarkers of acute coronary syndrome and heart failure, BNP or NTproBNP testing should be performed on a 24-h basis, and results should be provided with a turnaround time from blood collection within $60 \mathrm{~min}$. Point-ofcare testing is therefore favoured in cases for which the central laboratory cannot provide test results continuously within this time interval (22).
The cost-effectiveness of point-of-care testing has been reported with respect to length of stay in the coronary care unit (23), time to discharge from the emergency department (ED) (23) or from the hospital (24), and total treatment costs in the ED (24).

The Roche CARDIAC proBNP test (Roche Diagnostics $\mathrm{GmbH}$, Mannheim, Germany) is the first point-ofcare $(\mathrm{POC})$ test for the determination of NT-proBNP and the fourth test developed for the Roche cardiac reader system. The test uses one monoclonal and one polyclonal antibody for the quantitative measurement of NT-proBNP in heparinised whole blood. The test principle, using a biotinylated and a gold-labelled antibody and sandwich-type detection of the analyte, is comparable to the other tests of the Roche cardiac reader system, Roche cardiac T Quantitative, Roche CARDIAC M and Roche CARDIAC D-Dimer (25-27).

The measurement range of the test is between 60 and $3000 \mathrm{ng} / \mathrm{L}$. It is calibrated against the Elecsys proBNP comparison method using heparinised blood with the POC NT-proBNP test and heparinised plasma with the laboratory NT-proBNP test. The reaction time is approximately $12 \mathrm{~min}$ and the sample volume is $150 \mu \mathrm{L}$.

We present here the results of an analytical multicentre evaluation of the POC NT-proBNP test.

\section{Materials and methods}

\section{Analytical methods}

POC NT-proBNP measurements were performed using the Roche CARDIAC proBNP test with heparinised blood or quality control material (Roche CARDIAC Control proBNP Level Low and High; Roche Diagnostics). The instrument used was the Roche cardiac reader (Roche Diagnostics). Comparisons were made using the NT-proBNP assay on the Elecsys family of analysers (Roche Diagnostics) with heparinised plasma $(20,28,29)$

\section{Imprecision studies}

Within-series imprecision for blood samples and controls Imprecision was determined for native heparinised blood samples at four centres using 10 replicates of 52 samples. The imprecision was further determined at seven centres using 674 duplicate measurements for native heparinised blood samples and 317 and 312 duplicate measurements of the controls, with each replicate on a different instrument. All coefficients of variation (CVs) were calculated using the mean value (MV) and standard deviation (SD) for the duplicate or ten-fold series: $\mathrm{CV}, \%=\mathrm{SD} / \mathrm{MV} \times 100$.

Table 1 Within-series imprecision of the POC NT-proBNP method using patient blood samples or controls with four lots of POC NT-proBNP on two instruments.

\begin{tabular}{|c|c|c|c|c|}
\hline \multicolumn{3}{|l|}{ Blood samples } & \multicolumn{2}{|l|}{ Controls } \\
\hline \multicolumn{3}{|c|}{ Concentration range, ng/L } & \multirow{2}{*}{$\begin{array}{l}\text { Low level } \\
188 \mathrm{ng} / \mathrm{L}^{\mathrm{a}}\end{array}$} & \multirow{2}{*}{$\begin{array}{l}\text { High level } \\
1188 \mathrm{ng} / \mathrm{L}^{\mathrm{a}}\end{array}$} \\
\hline $60-125$ & $125-3000$ & $60-3000$ & & \\
\hline 9.6 & 7.8 & 8.1 & 7.9 & 7.4 \\
\hline $\mathrm{n}=99$ duplicates & $\mathrm{n}=575$ duplicates & $\mathrm{n}=674$ duplicates & $\mathrm{n}=317$ duplicates & $\mathrm{n}=313$ duplicates \\
\hline
\end{tabular}

Mean coefficients of variation $(\mathrm{CV}, \%)$ of the duplicates are shown. ${ }^{\text {a }}$ Mean value. 
A

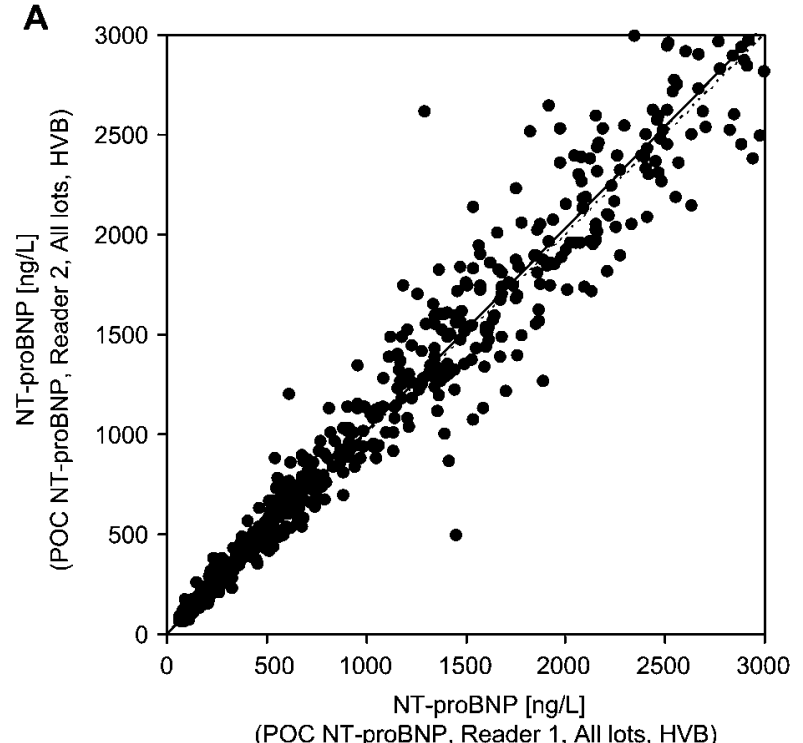

B

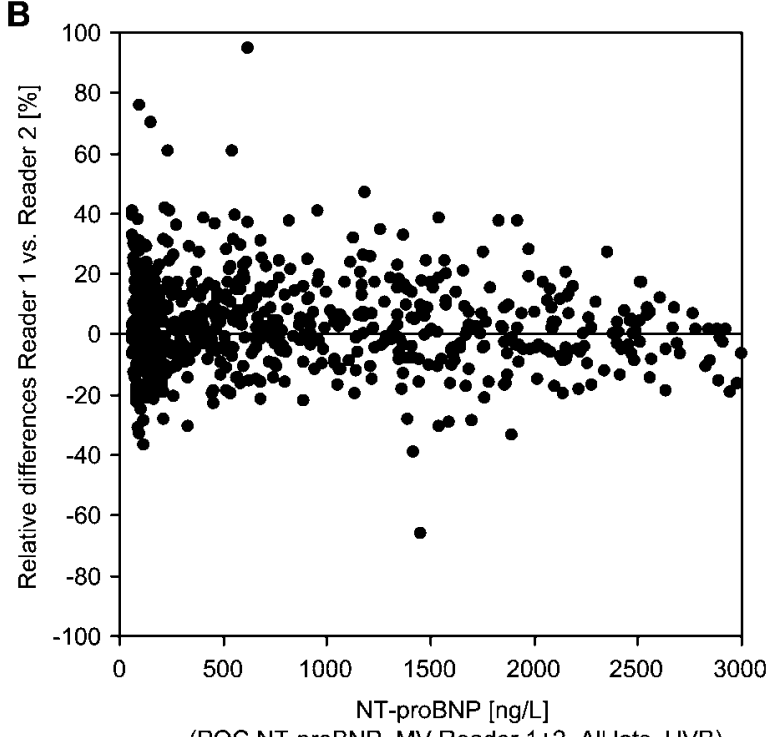

(POC NT-proBNP, MV Reader 1+2, All lots, HVB)

Figure 2 Comparison of duplicate measurements with two instruments: POC NT-proBNP, Reader 1, all lots, heparinised venous blood (HVB) vs. POC NT-proBNP, Reader 2, all lots, heparinised venous blood (HVB). $y=1.02 x+1.6$ (BablokPassing regression); $r=0.98 ; n=874$. MV, mean value. (A) Regression plot and (B) Bland-Altman plot.

Day-to-day imprecision for controls Day-to-day imprecision data were obtained from daily quality control measurements for 11-39 days (one sample/day per instrument). Only evaluation centres with a 10-day measurement period or longer were considered for the data analysis. Five centres fulfilled this criterion; two did not and were disregarded. The controls were freshly reconstituted each day and were measured on each instrument.

\section{Method comparisons with the laboratory NT-proBNP method}

Comparisons between the POC and laboratory NT-proBNP methods were carried out at seven centres. A total of 420 samples from patients with suspected heart failure and 168 samples from healthy volunteers were studied. Informed consent according to the Helsinki declaration was obtained

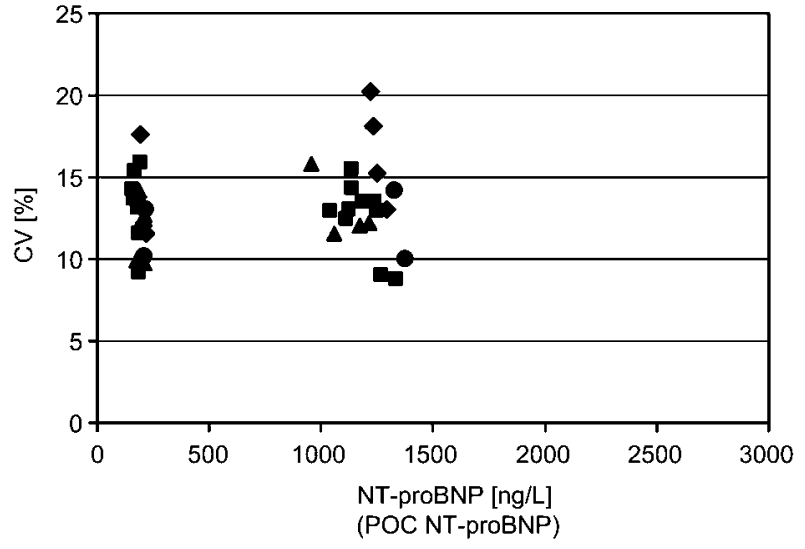

Figure 3 Day-to-day imprecision of POC NT-proBNP using system controls ( $\mathrm{n}=11-39$ days): $\mathbf{\text { lot }} 226382-30$; 226383-30; $\boldsymbol{\Delta}$ lot 226384-30; lot 226396-30. CV, coefficient of variation.
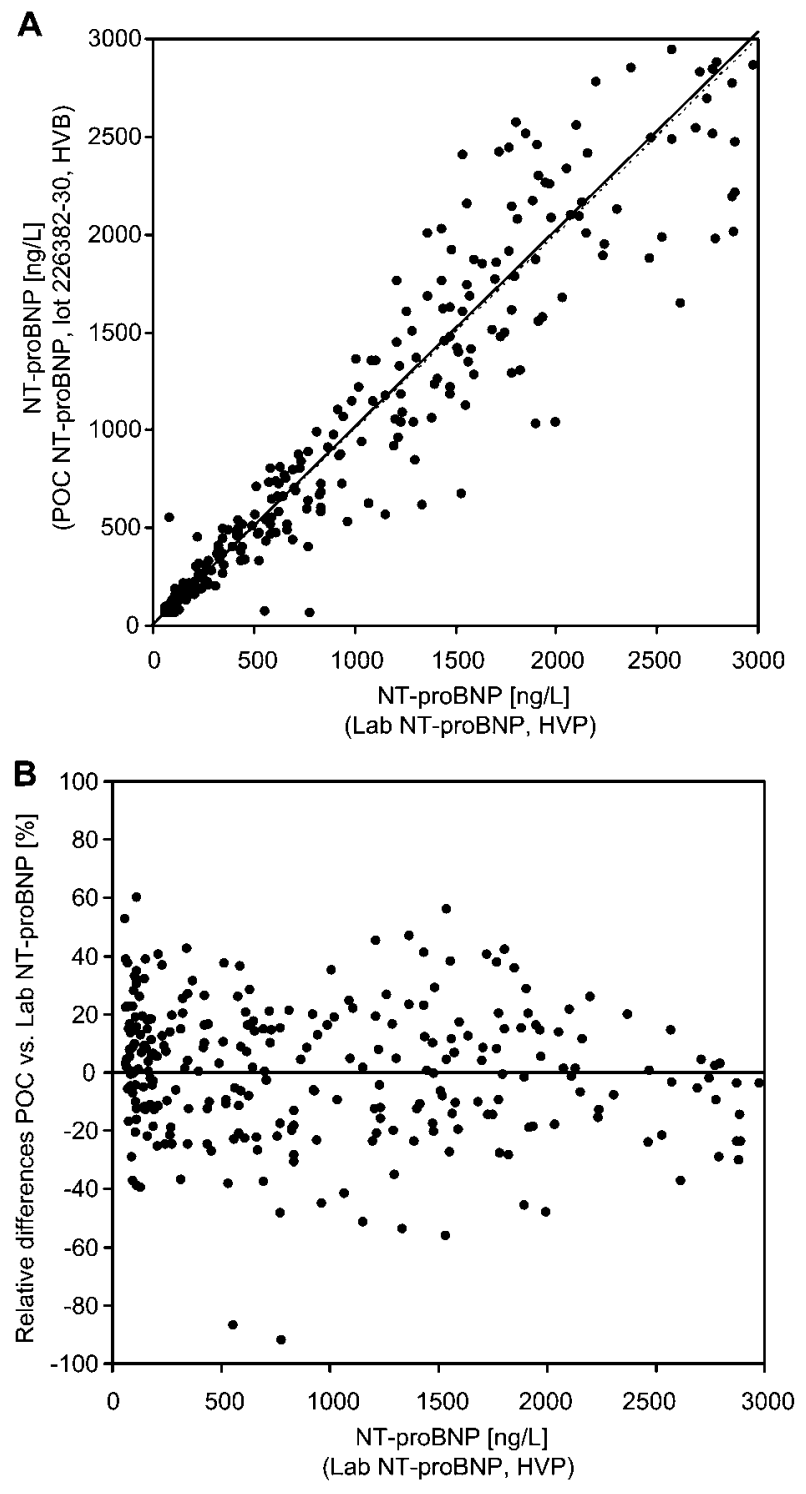

Figure 4 Method comparison with the laboratory method: POC NT-proBNP, lot 226382-30, heparinised venous blood (HVB) vs. laboratory NT-proBNP method, heparinised venous plasma (HVP). $y=1.01 x+3.9$ (Bablok-Passing regression); $r=0.95 ; n=279$. (A) Regression plot and (B) Bland-Altman plot. 
Table 2 Method comparisons for POC NT-proBNP (heparinised blood) vs. laboratory NT-proBNP (heparinised plasma).

\begin{tabular}{lllcllll}
\hline $\mathrm{x}$ & $\mathrm{y}$ & $\mathrm{n}$ & Median bias, $\%$ & Mean bias, \% & $\mathrm{r}$ & $\mathrm{a}$ & $\mathrm{b}$ \\
\hline Lab NT-proBNP & POC NT-proBNP, lot 226382 & 279 & 1.6 & 3.3 & 0.95 & 3.9 & 1.01 \\
Lab NT-proBNP & POC NT-proBNP, lot 226383 & 119 & -4.7 & 1.7 & 0.94 & 6.9 & 0.93 \\
Lab NT-proBNP & POC NT-proBNP, lot 226384 & 83 & 0.6 & 1.3 & 0.98 & 1.8 & 0.99 \\
Lab NT-proBNP & POC NT-proBNP, lot 226396 & 74 & 11.5 & 7.8 & 0.95 & 5.6 & 1.10 \\
\hline
\end{tabular}

Regression was calculated according to Passing and Bablok: $y=a+b \times x$, with $r$ the correlation coefficient.

from all patients and volunteers. Venous heparinised blood samples were collected and measured with the POC NTproBNP test within $4 \mathrm{~h}$. Samples were then centrifuged and the resulting plasma samples were deep-frozen and later analysed using the laboratory NT-proBNP test in one core laboratory.

\section{Comparison of sample materials}

At two centres the performance of the POC NT-proBNP method using arterial heparinised blood was compared with that for venous heparinised blood. A total of 62 venous and arterial heparinised blood samples were collected in parallel from patients undergoing cardiac catheterisation and were assayed using the POC NT-proBNP method.

\section{Lot-to-lot comparisons}

To verify the reproducibility of the calibration, four lots of the POC NT-proBNP test were investigated using fresh heparinised venous blood collected from 420 patients with suspected heart failure and from 168 healthy volunteers.

\section{Daily quality control}

Quality control of the POC NT-proBNP test comprised daily determination of the manufacturer's controls at each centre. Quality control of the laboratory NT-proBNP test was performed with the respective package controls during each run.

\section{Interference testing}

For interference testing, heparinised blood or plasma was spiked with biotin, bilirubin, rheumatoid factor, or drugs (for concentrations see Table 4; for concentrations of the drugs see Table 5) and with NT-proBNP pool serum. The NTproBNP pool serum was obtained from remainders of anonymised samples from dialysis patients.

To determine the potential interference of haemoglobin, patient blood samples were haemolysed by passing them multiple times through a syringe and needle. The resulting free haemoglobin concentrations in plasma were measured photometrically according to Fairbanks et al. (30). The recovery of spiked NT-proBNP concentrations before and after the haemolysis procedure was determined.

The POC NT-proBNP test uses the monoclonal antibody MAB-CK MM-M 33-IgG (MAB 33, Roche Diagnostics) as a blocking agent to avoid interference with human anti-mouse antibodies (HAMA). The influence of HAMA on POC NTproBNP was tested by adding MAB 33 and NT-proBNP to commercial HAMA type 1 and type 2 samples (Roche Diagnostics). Interference can be excluded if the recovery of NTproBNP in the sample does not change with increasing concentrations of the HAMA-blocking agent MAB 33 .

To determine the influence of haematocrit and triglycerides, method comparisons using the samples collected from patients with suspected congestive heart failure and from healthy volunteers were carried out.

\section{Influence of sample volume}

The sample volume dependence was investigated with volumes between 135 and $165 \mu \mathrm{L}$. Heparinised blood samples from healthy volunteers spiked with NT-proBNP were used in these experiments.

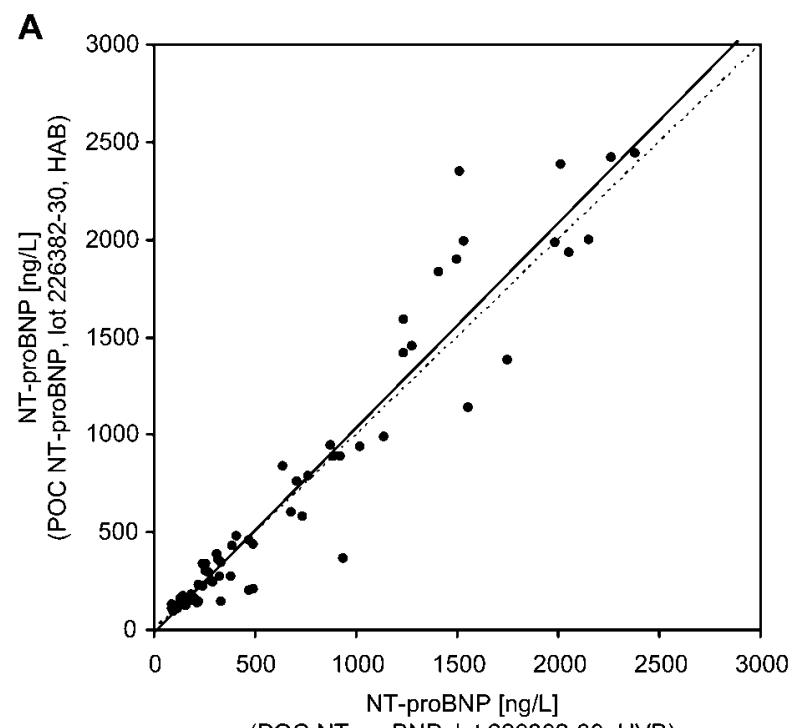

B (POC NT-proBNP, lot 226382-30, HVB)

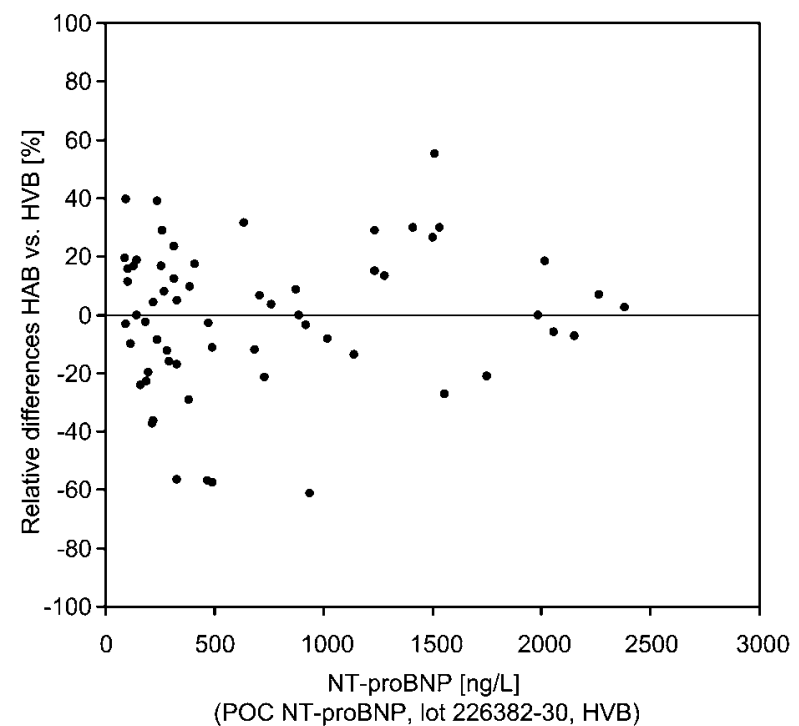

Figure 5 Comparison of sample materials: POC NT-proBNP, heparinised venous blood (HVB) vs. POC NT-proBNP, heparinised arterial blood (HAB). $y=1.05 x-12.8$ (Bablok-Passing regression); $r=0.96 ; n=62$. (A) Regression plot and (B) Bland-Altman plot. 

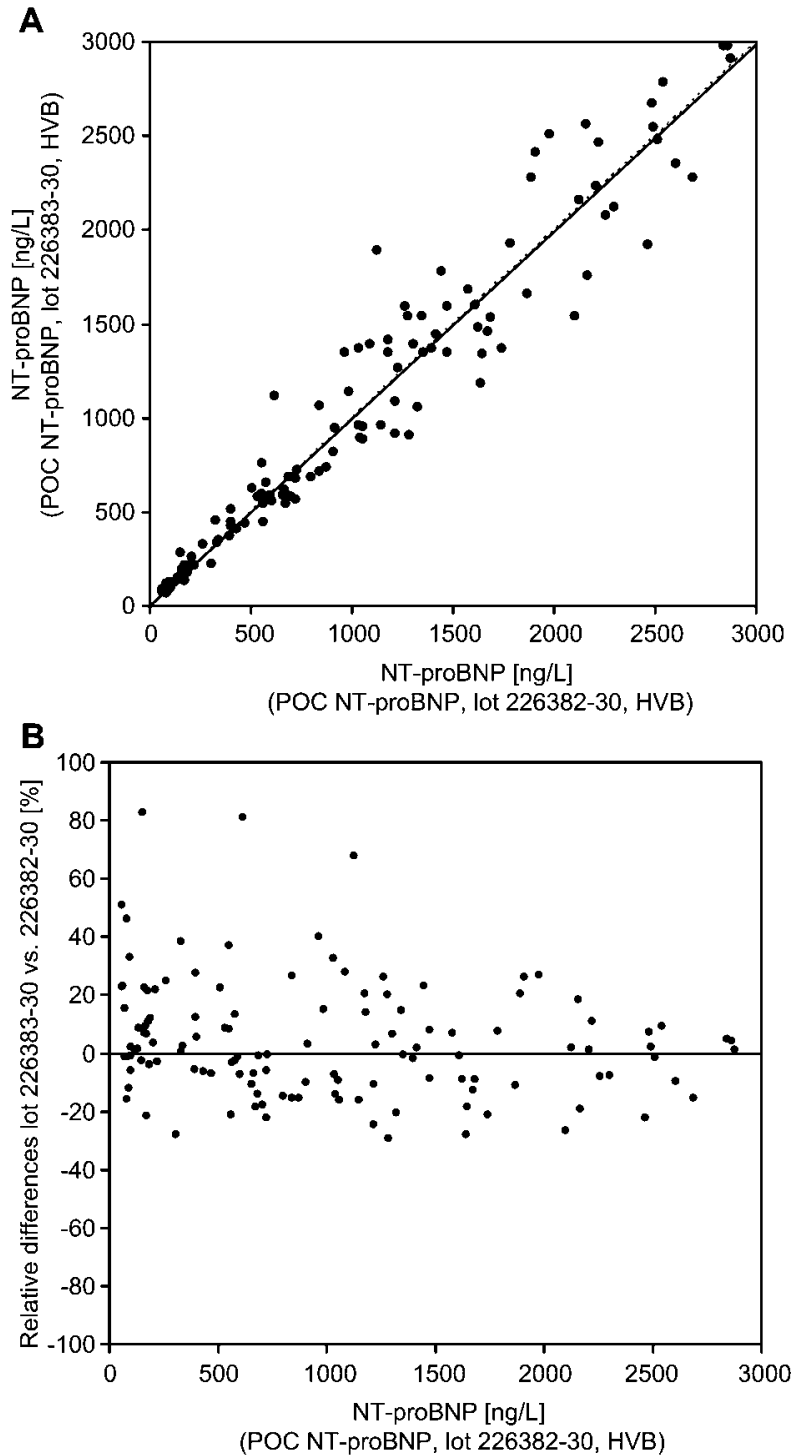

Figure 6 Lot-to-lot comparison with POC NT-proBNP. Lot 226382-30, heparinised venous blood (HVB) vs. lot 22638330 , heparinised venous blood. $y=1.00 x+2.6$ (Bablok-Passing regression); $r=0.97 ; n=125$. (A) Regression plot and (B) Bland-Altman plot.

\section{High-dose hook effect}

Immunoassays may yield false-negative results for samples containing very high analyte concentrations. This phenomenon is called the high-dose hook effect and is caused by saturation of all antibody binding sites with antigen, preventing formation of the expected sandwich complex. In investigations into the potential high-dose hook effect, heparinised blood samples from healthy donors were spiked with NT-proBNP up to a concentration of $35,000 \mathrm{ng} / \mathrm{L}$.

\section{Results and discussion}

\section{Within-series imprecision for blood samples and controls}

The majority of within-series CVs for 52 heparinised blood samples resulting from ten-fold measurements in the imprecision study (Figure 1), as well as the majority of within-series CVs for heparinised blood samples resulting from the 674 duplicate measurements in the method comparison, were below $10 \%$ (Table 1). A comparison of all 674 duplicate measurements between the two instruments and a Bland-Altman plot of the differences is shown in Figure 2.

The mean CVs for 317 or 313 duplicate measurements during daily quality control were $8 \%$ and $7 \%$ for the low and high POC NT-proBNP control levels, respectively (Table 1 ).

\section{Day-to-day imprecision and recovery for controls}

The CVs for day-to-day imprecision for the majority of samples were below $14 \%$ and $13 \%$ for the low and high POC NT-proBNP control levels, respectively (Figure 3).

For all 1276 measurements using the liquid controls, $100 \%$ were recovered within the target range given by the manufacturer.

\section{Method comparisons with the laboratory NT-proBNP test}

All lots of POC NT-proBNP showed very good agreement in method comparisons with the laboratory NTproBNP test. The median bias compared to the laboratory NT-proBNP method was between $-5 \%$ and $+12 \%$ for different lots of POC NT-proBNP. The slope for method comparison of POC NT-proBNP vs. laboratory NT-proBNP ranged between 0.93 and 1.10, and the intercept ranged between 1.8 and 6.9. The correlations in these comparisons were $\geq 0.94$ (Figure 4, Table 2).

\section{Comparison of sample materials}

There was good overall agreement between venous and arterial blood in comparisons using two lots of POC NT-proBNP. The bias found was $\leq 5 \%$ (Figure 5 ). This difference was similar to that found for the lotto-lot comparisons (see below).

Table 3 Lot-to-lot comparison for the POC NT-proBNP method.

\begin{tabular}{|c|c|c|c|c|c|c|c|}
\hline$x$ & y & $\mathrm{n}$ & Median bias, $\%$ & Mean bias, \% & $r$ & a & $\mathrm{b}$ \\
\hline POC NT-proBNP, lot 226382 & POC NT-proBNP, lot 226383 & 125 & 1.2 & 4.0 & 0.97 & 2.6 & 1.00 \\
\hline POC NT-proBNP, lot 226382 & POC NT-proBNP, lot 226384 & 88 & -1.7 & -1.3 & 0.99 & 8.7 & 0.95 \\
\hline POC NT-proBNP, lot 226382 & POC NT-proBNP, lot 226396 & 122 & -2.6 & -1.9 & 0.98 & 11.2 & 0.95 \\
\hline
\end{tabular}

Regression was calculated according to Passing and Bablok: $y=a+b \times x$, with $r$ the correlation coefficient. 


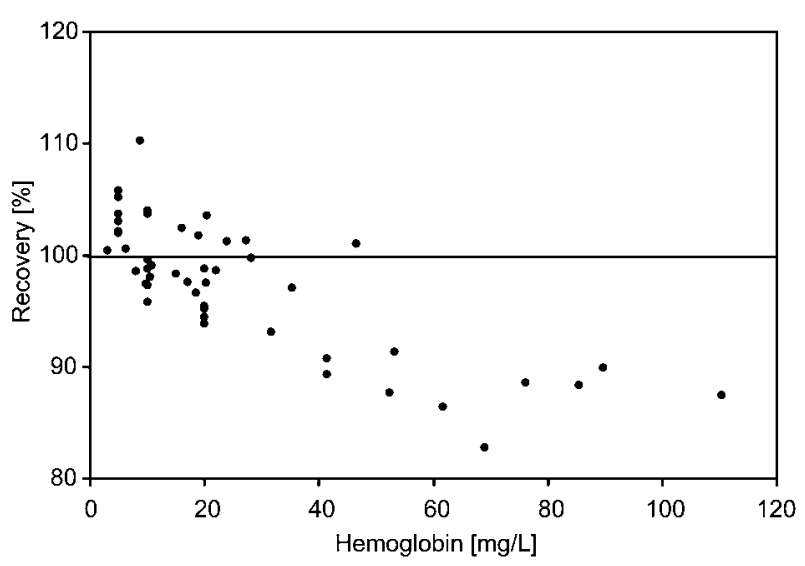

Figure 7 Influence of free plasma haemoglobin on results with POC NT-proBNP. The percentage relative recovery after haemolysis compared to the reference before haemolysis is shown.

\section{Lot-to-lot comparisons}

In comparisons of different lots of POC NT-proBNP, all lots showed excellent agreement, demonstrating the reproducibility of the calibration. The differences between the lots ranged from $-5 \%$ to $+4 \%$ (Figure 6 , Table 3).

\section{Interference testing}

The influence of haemoglobin on the POC NT-proBNP test result was within $\pm 7 \%$ up to a haemoglobin concentration of $35 \mathrm{mg} / \mathrm{L}$ and within $\pm 14 \%$ up to $62 \mathrm{mg} / \mathrm{L}$. At higher concentrations $(62-110 \mathrm{mg} / \mathrm{L})$, a lower recovery was observed in all samples $(n=5)$, one of which deviated by $>15 \%$ (Figure 7 ).

In investigations with biotin of up to $10 \mathrm{mg} / \mathrm{L}$, bilirubin up to $582 \mu \mathrm{mol} / \mathrm{L}$ and rheumatoid factor up to $42 \mathrm{IU} / \mathrm{mL}$ (Table 4) no analytical interference was

Table 4 Interference of biotin, bilirubin and rheumatoid factor with the POC NT-proBNP method.

\begin{tabular}{|c|c|c|c|}
\hline \multirow[t]{2}{*}{ Interferent } & \multicolumn{3}{|c|}{$\begin{array}{l}\text { NT-proBNP concentration } \\
\text { range, ng/L }\end{array}$} \\
\hline & $0-88$ & $89-222$ & $659-1557$ \\
\hline \multicolumn{4}{|l|}{ Biotin, mg/L } \\
\hline 0, reference & 100 & 100 & 100 \\
\hline 3 & $<$ LLMR & 90 & 93 \\
\hline 10 & $<$ LLMR & 92 & 99 \\
\hline 20 & $<$ LLMR & 84 & 101 \\
\hline 30 & $<$ LLMR & 83 & 85 \\
\hline \multicolumn{4}{|c|}{ Bilirubin, $\mu \mathrm{mol} / \mathrm{L}$} \\
\hline 0 , reference & 100 & 100 & 100 \\
\hline 342 & 96 & 99 & 101 \\
\hline 582 & 93 & 96 & 102 \\
\hline \multicolumn{4}{|c|}{ Rheumatoid factor, IU/mL } \\
\hline 0, reference & 100 & 100 & 100 \\
\hline 16 & $<$ LLMR & 89 & 90 \\
\hline 42 & $<$ LLMR & 97 & 96 \\
\hline 52 & $<$ LLMR & 93 & 78 \\
\hline 181 & $<$ LLMR & 66 & 73 \\
\hline
\end{tabular}

The percentage relative recovery compared to the reference is reported. <LLMR, below the lower limit of the measuring range.
Table 5 Interference of haemotocrit with the POC NTproBNP method, reported as the relative recovery of NTproBNP concentrations (measured using the laboratory NT-proBNP method) for the POC NT-proBNP method.

\begin{tabular}{llr}
\hline Haematocrit, \% & Median recovery, \% & $\mathrm{n}$ \\
\hline $28-34$ & 101 & 38 \\
$35-44$ & 108 & 289 \\
$45-58$ & 111 & 43 \\
\hline
\end{tabular}

Table 6 Interference of triglycerides with the POC NTproBNP method, reported as the relative recovery of NTproBNP concentrations (measured using the laboratory NT-proBNP method) for the POC NT-proBNP method.

\begin{tabular}{llr}
\hline $\begin{array}{l}\text { Triglyceride concentration, } \\
\mathrm{mmol} / \mathrm{L}\end{array}$ & $\begin{array}{l}\text { Median recovery, } \\
\%\end{array}$ \\
\hline $0-1.9$ & 106 & 153 \\
$2.0-3.9$ & 107 & 60 \\
$4.0-6.3$ & 89 & 14 \\
\hline
\end{tabular}

detected, i.e., all deviations from expected values were $\leq 15 \%$.

The recovery of laboratory NT-proBNP concentrations according to the POC NT-proBNP test was between $101 \%$ and $111 \%$ for the haematocrit range studied (Table 5). Moreover there was no correlation between haematocrit and the relative POC NT-proBNP/laboratory NT-proBNP method differences $(r=0.16)$, indicating no influence on the result by haematocrit values between $28 \%$ and $58 \%$.

There was no influence of triglycerides at up to $6.3 \mathrm{mmol} / \mathrm{L}$, as demonstrated by recoveries from $89 \%$ to $107 \%$ (Table 6 ). The correlation coefficient between triglyceride concentration and the relative POC NTproBNP/lab NT-proBNP method differences was low $(r=-0.05)$.

The interference of drugs was tested with toxic concentrations of each drug and was repeated with therapeutic concentrations if an influence was found. At therapeutic concentrations, 50 out of the 52 drugs investigated did not influence the POC NT-proBNP result by more than $\pm 15 \%$. With bisoprolol and BNP, somewhat higher bias in the low NT-proBNP concentration range ( $<175 \mathrm{ng} / \mathrm{L})$ was found, which did not exceed $\pm 33 \mathrm{ng} / \mathrm{L}$ in absolute terms (Table 7).

With HAMA serum type 1 and type 2, the recovery was reduced or elevated if MAB 33 was added. Thus, interference from HAMA type 1 and type 2 positive sera was not completely eliminated (Table 8).

\section{Influence of sample volume}

There was a slight trend to lower recovery when low sample volumes were applied to the test compared to the regular volume of $150 \mu \mathrm{L}$, but overdosing or underdosing by $10 \mu \mathrm{L}$ did not affect the test result significantly (Figure 8). Insufficient filling of the test strip should be avoided by using a professional laboratory pipette or the POC system pipette supplied by the manufacturer. 
Table 7 Interference of drugs with the POC NT-proBNP method.

\begin{tabular}{|c|c|c|c|}
\hline \multirow[t]{2}{*}{ Drug } & \multicolumn{3}{|c|}{ NT-proBNP concentration range, ng/L } \\
\hline & $0-106$ & $107-241$ & $864-1519$ \\
\hline No drug, reference & 100 & 100 & 100 \\
\hline Acetaminophen, $200 \mu \mathrm{g} / \mathrm{mL}$ & 85 & 91 & 93 \\
\hline Acetylcysteine, $150 \mu \mathrm{g} / \mathrm{mL}$ & 101 & 128 & 118 \\
\hline Acetylcysteine, $30 \mu \mathrm{g} / \mathrm{mL}$ & $<$ LLMR & 99 & 105 \\
\hline Acetylsalicylic acid, $1 \mathrm{mg} / \mathrm{mL}$ & 108 & 110 & 107 \\
\hline Adrenaline, $0.37 \mu \mathrm{g} / \mathrm{mL}$ & $<$ LLMR & 84 & 86 \\
\hline Adrenaline, $0.074 \mu \mathrm{g} / \mathrm{mL}$ & $<$ LLMR & 91 & 97 \\
\hline Ampicillin, $1.0 \mathrm{mg} / \mathrm{mL}$ & $<$ LLMR & 98 & 82 \\
\hline Ampicillin, $0.2 \mathrm{mg} / \mathrm{mL}$ & $<$ LLMR & 106 & 98 \\
\hline Ascorbic acid, $300 \mu \mathrm{g} / \mathrm{mL}$ & $<$ LLMR & 91 & 96 \\
\hline Bisoprolol, $10 \mu \mathrm{g} / \mathrm{mL}$ & $<$ LLMR & 87 & 83 \\
\hline Bisoprolol, $2 \mu \mathrm{g} / \mathrm{mL}$ & ND & 117 & 107 \\
\hline $\mathrm{BNP}, 25 \mu \mathrm{g} / \mathrm{mL}$ & $<$ LLMR & 123 & 113 \\
\hline Ca-Dobesilate, $200 \mu \mathrm{g} / \mathrm{mL}$ & $<$ LLMR & 87 & 88 \\
\hline Captopril, $150 \mu \mathrm{g} / \mathrm{mL}$ & 108 & 100 & 95 \\
\hline Carvedilol, $50 \mu \mathrm{g} / \mathrm{mL}$ & $<$ LLMR & 94 & 98 \\
\hline Cefoxitin, $2.5 \mathrm{mg} / \mathrm{mL}$ & 87 & 59 & 48 \\
\hline Cefoxitin, $0.5 \mathrm{mg} / \mathrm{mL}$ & $<$ LLMR & 94 & 95 \\
\hline Cyclosporin, $5 \mu \mathrm{g} / \mathrm{mL}$ & 108 & 101 & 91 \\
\hline Digitoxin, $0.3 \mu \mathrm{g} / \mathrm{mL}$ & $<$ LLMR & 85 & 93 \\
\hline Digoxin, $0.5 \mu \mathrm{g} / \mathrm{mL}$ & $<$ LLMR & 88 & 91 \\
\hline Doxycyclin, $50 \mu \mathrm{g} / \mathrm{mL}$ & $<$ LLMR & 94 & 98 \\
\hline Enalapril maleate, $40 \mu \mathrm{g} / \mathrm{mL}$ & $<$ LLMR & 83 & 91 \\
\hline Enalapril maleate, $8 \mu \mathrm{g} / \mathrm{mL}$ & $<$ LLMR & 99 & 97 \\
\hline Gentamicin, $0.5 \mathrm{mg} / \mathrm{mL}$ & $<$ LLMR & 85 & 83 \\
\hline Gentamicin, $0.1 \mathrm{mg} / \mathrm{mL}$ & $<$ LLMR & 94 & 101 \\
\hline Glycerol trinitrate, $192 \mu \mathrm{g} / \mathrm{mL}$ & $<$ LLMR & 91 & 96 \\
\hline Heparin, unfractionated, $5000 \mathrm{U} / \mathrm{L}$ & $<$ LLMR & 93 & 111 \\
\hline Heparin, LMW, $29 \mu \mathrm{g} / \mathrm{mL}$ & $<$ LLMR & 106 & 93 \\
\hline Ibuprofen, $500 \mu \mathrm{g} / \mathrm{mL}$ & ND & 87 & 89 \\
\hline Ibuprofen, $100 \mu \mathrm{g} / \mathrm{mL}$ & $<$ LLMR & 88 & 91 \\
\hline Insulin, $840 \mu \mathrm{g} / \mathrm{mL}$ & $<$ LLMR & 93 & 93 \\
\hline Intralipid, $10 \mathrm{mg} / \mathrm{mL}$ & $<$ LLMR & 92 & 101 \\
\hline Levodopa, $20 \mu \mathrm{g} / \mathrm{mL}$ & 100 & 100 & 96 \\
\hline Lidocaine, $100 \mu \mathrm{g} / \mathrm{mL}$ & $<$ LLMR & 102 & 98 \\
\hline Lisinopril dehydrate, $40 \mu \mathrm{g} / \mathrm{mL}$ & ND & 107 & 85 \\
\hline Lisinopril dehydrate, $8 \mu \mathrm{g} / \mathrm{mL}$ & $<$ LLMR & 87 & 100 \\
\hline Lovastatin, $80 \mu \mathrm{g} / \mathrm{mL}$ & $<$ LLMR & 81 & 83 \\
\hline Lovastatin, $16 \mu \mathrm{g} / \mathrm{mL}$ & ND & ND & 100 \\
\hline Methyldopa, $20 \mu \mathrm{g} / \mathrm{mL}$ & 84 & 92 & 101 \\
\hline Methylprednisolone, $80 \mu \mathrm{g} / \mathrm{mL}$ & $<$ LLMR & 102 & 94 \\
\hline Metoprolol, $15 \mu \mathrm{g} / \mathrm{mL}$ & $<$ LLMR & 92 & 88 \\
\hline Metronidazole, $200 \mu \mathrm{g} / \mathrm{mL}$ & 102 & 92 & 91 \\
\hline Molsidomine, $24 \mu \mathrm{g} / \mathrm{mL}$ & $<$ LLMR & 90 & 108 \\
\hline Nicardipine, $90 \mu \mathrm{g} / \mathrm{mL}$ & $<$ LLMR & 96 & 95 \\
\hline Nifedipine, $60 \mu \mathrm{g} / \mathrm{mL}$ & $<$ LLMR & 92 & 92 \\
\hline Phenprocoumon, $6 \mu \mathrm{g} / \mathrm{mL}$ & $<$ LLMR & 90 & 92 \\
\hline Phenylbutazone, $400 \mu \mathrm{g} / \mathrm{mL}$ & 114 & 91 & 81 \\
\hline Phenylbutazone, $80 \mu \mathrm{g} / \mathrm{mL}$ & 121 & 106 & 103 \\
\hline Pravastatin, $40 \mu \mathrm{g} / \mathrm{mL}$ & $<$ LLMR & 90 & 80 \\
\hline Pravastatin, $8 \mu \mathrm{g} / \mathrm{mL}$ & $<$ LLMR & 107 & 100 \\
\hline Propafenone, $900 \mu \mathrm{g} / \mathrm{mL}$ & $<$ LLMR & $<$ LLMR & 60 \\
\hline Propafenone, $180 \mu \mathrm{g} / \mathrm{mL}$ & $<$ LLMR & 91 & 97 \\
\hline Propranolol, $0.32 \mu \mathrm{g} / \mathrm{mL}$ & 129 & 109 & 105 \\
\hline Propranolol, $0.064 \mu \mathrm{g} / \mathrm{mL}$ & $<$ LLMR & 99 & 101 \\
\hline Renin, $205 \mu \mathrm{U} / \mathrm{mL}$ & 91 & 102 & 86 \\
\hline Reteplase, $1.12 \mu \mathrm{g} / \mathrm{mL}$ & 120 & 106 & 93 \\
\hline Rifampicin, $60 \mu \mathrm{g} / \mathrm{mL}$ & 111 & 102 & 92 \\
\hline Simvastatin, $40 \mu \mathrm{g} / \mathrm{mL}$ & ND & 115 & 92 \\
\hline Simvastatin, $8 \mu \mathrm{g} / \mathrm{mL}$ & $<$ LLMR & 89 & 99 \\
\hline Sotalol, $320 \mu \mathrm{g} / \mathrm{mL}$ & $<$ LLMR & 106 & 93 \\
\hline Spironolactone, $400 \mu \mathrm{g} / \mathrm{mL}$ & $<$ LLMR & 110 & 103 \\
\hline Streptokinase, $300 \mathrm{IE}$ & $<$ LLMR & 94 & 107 \\
\hline Theophylline, $1.0 \mu \mathrm{g} / \mathrm{mL}$ & $<$ LLMR & 80 & 85 \\
\hline Theophylline, $0.2 \mu \mathrm{g} / \mathrm{mL}$ & $<$ LLMR & 89 & 94 \\
\hline Tolbutamide, $3 \mu \mathrm{g} / \mathrm{mL}$ & $<$ LLMR & 89 & 91 \\
\hline Torasemide, $200 \mu \mathrm{g} / \mathrm{mL}$ & $<$ LLMR & 84 & 68 \\
\hline
\end{tabular}


(Table 7 continued)

\begin{tabular}{|c|c|c|c|}
\hline \multirow[t]{2}{*}{ Drug } & \multicolumn{3}{|c|}{ NT-proBNP concentration range, ng/L } \\
\hline & $0-106$ & $107-241$ & 864-1519 \\
\hline Torasemide, $40 \mu \mathrm{g} / \mathrm{mL}$ & $<$ LLMR & 104 & 90 \\
\hline Urokinase, $34.5 \mathrm{U}$ & $<$ LLMR & 101 & 109 \\
\hline Verapamil, $120 \mu \mathrm{g} / \mathrm{mL}$ & $<$ LLMR & 84 & 100 \\
\hline Verapamil, $24 \mu \mathrm{g} / \mathrm{mL}$ & $<$ LLMR & 97 & 91 \\
\hline
\end{tabular}

The percentage relative recovery compared to the reference is reported. A second, lower therapeutic concentration of a drug was tested if an influence was found with the higher toxic concentration. <LLMR, below the lower limit of the measuring range; ND, not determined.

Table 8 Interference of HAMA sera with the POC NT-proBNP method.

\begin{tabular}{|c|c|c|c|}
\hline \multirow[t]{2}{*}{ Interferent } & \multirow[t]{2}{*}{$\mathrm{MAB} 33, \mathrm{mg} / \mathrm{mL}$} & \multicolumn{2}{|c|}{ NT-proBNP concentration range, ng/L } \\
\hline & & $0-60$ & $337-366$ \\
\hline \multirow[t]{4}{*}{ HAMA type 1} & 0, reference & 100 & 100 \\
\hline & 0.1 & $<$ LLMR & 105 \\
\hline & 1 & $<$ LLMR & 100 \\
\hline & 10 & $<$ LLMR & 86 \\
\hline \multirow[t]{4}{*}{ HAMA type 2} & 0, reference & 100 & 100 \\
\hline & 0.1 & $<$ LLMR & 111 \\
\hline & 1 & $<$ LLMR & 117 \\
\hline & 10 & <LLMR & 99 \\
\hline
\end{tabular}

The percentage relative recovery after addition of HAMA-blocking agent MAB 33 compared to the reference without MAB 33 is reported. <LLMR, below the lower limit of the measuring range.

\section{High-dose hook effect}

High NT-proBNP concentrations above the measuring range of the POC NT-proBNP test did not lead to falsenegative or false low results due to a potential highdose hook effect. With NT-proBNP concentrations between 10,000 and $35,000 \mathrm{ng} / \mathrm{L}$, the instrument displayed either "High $>3000 \mathrm{pg} / \mathrm{mL}^{\prime}$ or an error message. If a quantitative result in this range is needed, the measurement has to be repeated with a laboratory NT-proBNP method.

\section{Conclusions}

With the new POC NT-proBNP test, reliable quantitative NT-proBNP results can easily be obtained within

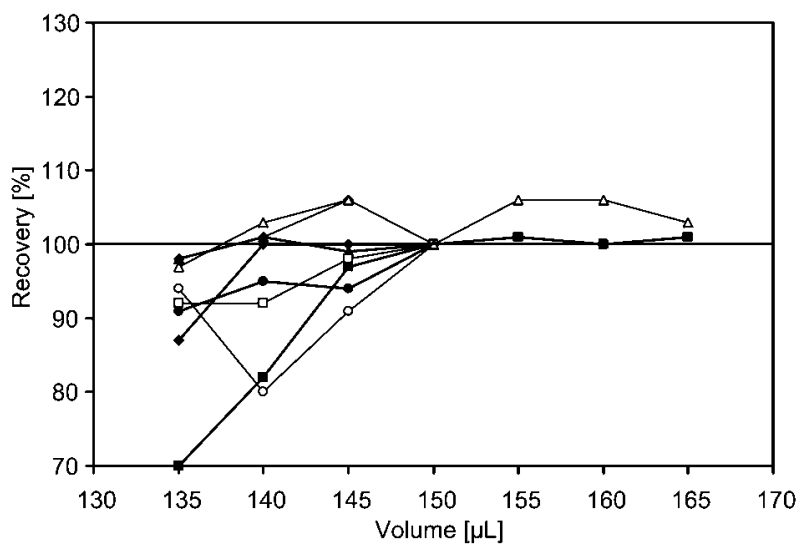

Figure 8 Influence of sample volume on POC NT-proBNP results. NT-proBNP concentrations: $156 \mathrm{ng} / \mathrm{L}$; $147 \mathrm{ng} / \mathrm{L}$; - $131 \mathrm{ng} / \mathrm{L} ; \boldsymbol{\Delta} 127 \mathrm{ng} / \mathrm{L} ; \square 144 \mathrm{ng} / \mathrm{L} ; \bigcirc 115 \mathrm{ng} / \mathrm{L} ; \diamond 186$ $\mathrm{ng} / \mathrm{L} ; \triangle 1345 \mathrm{ng} / \mathrm{L}$. Mean recoveries of 20 replicates per volume are shown. less than 15 min. Owing to its excellent analytical concordance with the laboratory NT-proBNP test, we expect a similar diagnostic performance for this assay. The test should therefore be well suited to its intended use as an aid in the diagnosis of patients suspected of having congestive heart failure, in the monitoring of patients with compensated left-ventricular dysfunction, and in the risk stratification of patients with acute coronary syndromes.

A higher level of evidence for its clinical utility may be obtained in clinical studies using the POC NTproBNP test. Hence, a prospective trial on the efficacy of the POC NT-proBNP test in treatment guidance for chronic heart failure patients in heart failure clinics was designed and is currently ongoing.

\section{Acknowledgements}

CARDIAC and Elecsys are trademarks of a member of the Roche group.

\section{References}

1. Sharpe N, Doughty R. Epidemiology of heart failure and ventricular dysfunction. Lancet 1998;352(Suppl 1):3-7.

2. Lloyd-Jones DM, Larson MG, Leip EP, Beiser A, D'Agostino RB, Kannel WB, et al. Lifetime risk for developing congestive heart failure - The Framingham Heart Study. Circulation 2002;106:3068-72.

3. Nieminen MS, Böhm M, Cowie MR, Drexler H, Filippatos GS, Jondeau G, et al. Executive summary of the guidelines for the diagnosis and treatment of acute heart failure. The Task Force on Acute Heart Failure of the European Society of Cardiology. Eur Heart J 2005;26: 384-416. 
4. Swedberg K, Cleland J, Dargie H, Drexler H, Follath F, Komajda M, et al. Guidelines for the diagnosis and treatment of chronic heart failure: executive summary (update 2005). The Task Force for the Diagnosis and Treatment of Chronic Heart Failure of the European Society of Cardiology. Eur Heart J 2005;26:1115-40.

5. Lainchbury JG, Campbell E, Frampton CM, Yandle TG, Nicholls MG, Richards AM. Brain natriuretic peptide and $\mathrm{N}$-terminal brain natriuretic peptide in the diagnosis of heart failure in patients with acute shortness of breath. J Am Coll Cardiol 2003;42:728-35.

6. Bayés-Genís A, Santaló-Bel M, Zapico-Muñiz E, López L, Cotes $\mathrm{C}$, Bellido J, et al. N-Terminal probrain natriuretic peptide (NT-proBNP) in the emergency diagnosis and inhospital monitoring of patients with dyspnoea and ventricular dysfunction. Eur J Heart Fail 2004;6:301-8.

7. Januzzi JL, Camargo CA, Anwaruddin S, Baggish AL, Chen AA, Krauser DG, et al. The N-terminal pro-BNP investigation of dyspnea in the emergency department (PRIDE) study. Am J Cardiol 2005;95:948-54.

8. Januzzi JL, van Kimmenade R, Lainchbury J, BayesGenis A, Ordóñez-Llanos J, Santaló-Bel M, et al. NTproBNP testing for diagnosis and short-term prognosis in acute destabilized heart failure: an international pooled analysis of 1256 patients. Eur Heart J 2006;27:330-7.

9. Hobbs FD, Davis RC, Roalfe AK, Hare R, Davies MK, Kenkre JE. Reliability of $\mathrm{N}$-terminal pro-brain natriuretic peptide assay in diagnosis of heart failure: cohort study in representative and high risk community populations. Br Med J 2002;324:1498-502.

10. Wright SP, Doughty RN, Pearl A, Gamble GD, Whalley $\mathrm{GA}$, Walsh $\mathrm{HJ}$, et al. Plasma amino-terminal pro-brain natriuretic peptide and accuracy of heart-failure diagnosis in primary care. A randomized, controlled trial. J Am Coll Cardiol 2003;42:1793-800.

11. Bettencourt P. NT-proBNP and BNP: biomarkers for heart failure management. Eur J Heart Fail 2004;6:35963.

12. Hartmann F, Packer M, Coats AJS, Fowler MB, Krum H, Mohacsi $\mathrm{P}$, et al. Prognostic impact of plasma N-terminal pro-brain natriuretic peptide in severe chronic congestive heart failure. A substudy of the Carvedilol Prospective Randomized Cumulative Survival (COPERNICUS) Trial. Circulation 2004;110:1780-6.

13. Kirk V, Bay M, Parner J, Krogsgaard K, Herzog TM, Boesgaard $\mathrm{S}$, et al. N-Terminal proBNP and mortality in hospitalized patients with heart failure and preserved vs. reduced systolic function: data from the prospective Copenhagen Hospital Heart Failure Study (CHHF). Eur J Heart Fail 2004;6:335-41.

14. Gardner RS, Chong KS, Morton JJ, McDonagh TA. NTerminal brain natriuretic peptide, but not anemia, is a powerful predictor of mortality in advanced heart failure. J Card Fail 2005;11(Suppl):47-53.

15. George J, Patal S, Wexler D, Abashidze A, Shmilovich H, Barak $T$, et al. Circulating erythropoietin levels and prognosis in patients with congestive heart failure: comparison with neurohormonal and inflammatory markers. Arch Intern Med 2005;165:1304-9.

16. Kellett J. The prediction of in-hospital mortality by amino terminal pro-brain natriuretic peptide (NT-proBNP) levels and other independent variables in acutely ill patients with suspected heart disease. Eur J Int Med 2005;16:195-9.

17. Troughton RW, Frampton CM, Yandle TG, Espiner EA, Nicholls MG, Richards AM. Treatment of heart failure guided by plasma aminoterminal brain natriuretic peptide (N-BNP) concentrations. Lancet 2000;355:1126-30.

18. Groenning BA, Nilsson JC, Sondergaard L, Pedersen F, Trawinski J, Baumann M, et al. Detection of left ventricular enlargement and impaired systolic function with plasma $\mathrm{N}$-terminal pro brain natriuretic peptide concentrations. Am Heart J 2002;143:923-9.

19. Hunt PJ, Espiner EA, Nicholls MG, Richards AM, Yandle TG. The role of the circulation in processing pro-brain natriuretic peptide (proBNP) to amino-terminal BNP and BNP-32. Peptides 1997;18:1475-81.

20. Yeo KT, Wu AH, Apple FS, Kroll MH, Christenson RH, Lewandrowski KB, et al. Multicenter evaluation of the Roche NT-proBNP assay and comparison to the Biosite Triage BNP assay. Clin Chim Acta 2003;338:107-15.

21. van der Merwe D, Henly R, Lane G, Field R, Frenneaux $M$, Dunstan $F$, et al. Effect of different sample types and stability after blood collection of N-terminal pro-B-type natriuretic peptide as measured with Roche Elecsys System. Clin Chem 2004;50:779-80.

22. The National Academy of Clinical Biochemistry. Laboratory medicine practice guidelines: biomarkers of acute coronary syndrome and heart failure. Draft Guidelines, Version 2. http://www.nacb.org.

23. Blick KE. Economics of point-of-care (POC) testing for cardiac markers and B-natriuretic peptide (BNP). Point Care J 2005;4:11-4.

24. Mueller C, Scholer A, Laule-Kilian K, Martina B, Schindler $C$, Buser $P$, et al. Use of B-type natriuretic peptide in the evaluation and management of acute dyspnea. $\mathrm{N}$ Engl J Med 2004;350:647-54.

25. Müller-Bardorff M, Sylvén C, Rasmanis G, Jørgensen B, Collinson PO, Waldenhofer $U$, et al. Evaluation of a point-of-care system for quantitative determination of troponin T and myoglobin. Clin Chem Lab Med 2000; 38:567-74.

26. Collinson PO, Jørgensen B, Sylvén C, Haass M, Chwallek $F$, Katus HA, et al. Recalibration of the point-of-care test for Cardiac T Quantitative with Elecsys Troponin T 3rd generation. Clin Chim Acta 2001;307:197-203.

27. Dempfle CE, Schraml M, Besenthal I, Hansen R, Gehrke $\mathrm{J}$, Korte W, et al. Multicenter evaluation of a new pointof-care test for the quantitative determination of $D$ dimer. Clin Chim Acta 2001;307:211-8.

28. Collinson PO, Barnes SC, Gaze DC, Galasko G, Lahiri A, Senior R. Analytical performance of the $\mathrm{N}$ terminal pro $\mathrm{B}$ type natriuretic peptide (NT-proBNP) assay on the Elecsys 1010 and 2010 analysers. Eur J Heart Fail 2004; 6:365-8.

29. Sokoll LJ, Baum H, Collinson PO, Gurr E, Haass M, Luthe $\mathrm{H}$, et al. Multicenter analytical performance evaluation of the Elecsys proBNP assay. Clin Chem Lab Med 2004;42: 965-72.

30. Fairbanks VF, Ziesmer SC, O'Brian PC. Methods for measuring plasma hemoglobin in micromolar concentration compared. Clin Chem 1992;38:132-40.

Received May 19, 2006, accepted July 7, 2006 